\title{
Impact of Plug-in Electric Vehicles on the Supply Grid
}

Josep Balcells, Universitat Politècnica de Catalunya, Electronics Eng. Dept., Colom 1, 08222 Terrassa, Spain

Josep García, CIRCUTOR SA, Vial sant Jordi, s/n, 08232, Viladecavalls, Spain

\section{Abstract}

This paper presents a case study describing the impact of charging process of plug in hybrid vehicles (PHEV) and all electrical vehicles (EV) on the supply grid. The paper shows the distortion produced in the grid by the simultaneous charge of a large fleet of vehicles and the corrective actions taken to guarantee the Electromagnetic Compatibility with other loads in the same grid. The goal of the investigation was to establish a design guide for parking facilities

\section{Introduction}

Effective transportation systems are essential for developed countries prosperity having significant impacts on economic growth, social development and the environment. In 2004 the transport sector consumed $30 \%$ of the total final energy consumption and it was responsible for $25 \%$ of $\mathrm{CO} 2$ emissions (EU-25) [1]

Plug-in hybrid-electric vehicles (PHEV) and all electrical vehicles (EV) have recently emerged as a promising alternative that use electricity to displace a significant fraction of fleet petroleum consumption. Moreover, several recent studies show that electric- drive vehicles (EDVs) may even profitably provide power to the grid while they are parked and connected to electrical grid. This is called Vehicle to Grid power (V2G) [2-4].

Nevertheless, this new situation and the predictable future growth of EVs and PHEVs, creates serious problems of power quality in existing grids, mainly where parking installations are concentrated [3, 5-9].

Table 1.- Main features of the fully electric vehicles already present in the market [1]

\begin{tabular}{|c|c|c|c|c|c|c|}
\hline & Brand & Model & $\begin{array}{c}\text { Capacity } \\
\text { (kWh) }\end{array}$ & $\begin{array}{c}\text { Range } \\
(\mathrm{km})\end{array}$ & $\begin{array}{l}\text { Consumption } \\
(\mathrm{kWh} / 100 \mathrm{~km})\end{array}$ & Classification \\
\hline \multirow{11}{*}{ 党 } & Renault & Twingo Quickshift E & 21.45 & 129 & 16.60 & olMedium \\
\hline & fiat & Panda & 19.68 & 120 & 16.40 & gedium \\
\hline & NICE & Mega City & 10.50 & 80 & 13.05 & 5 Small \\
\hline & FIAT & 500 & 22.00 & 113 & 19.53 & 3 Medium \\
\hline & Mitsubishi & -MIEV & 20.00 & 160 & 12.50 & olMedium \\
\hline & MINI & MINI-E & 35.00 & 180 & 19,44 & 4 Big \\
\hline & TESLA & Roadster/Model S & 55.00 & 300 & 18.33 & 3 Big \\
\hline & CODA & CODA-EV & 33.80 & 180 & 18.78 & 8 Big \\
\hline & lighting & GTS & 35.00 & 175 & 20.00 & oBig \\
\hline & MILES & ZX40S/ZX40ST & 10.00 & 105 & & 6 small \\
\hline & Phoenix & SUV/SUT & 35.00 & 209 & 16.73 & 3 Medium \\
\hline \multirow{3}{*}{ 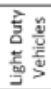 } & AlKè & ATX & 8.40 & 70 & 12.00 & QLDV \\
\hline & Piaggio & Porter & 25.74 & 110 & 23.40 & gLDV \\
\hline & LDV & Maxus Electric & & 160 & & LDV \\
\hline
\end{tabular}


Table 2.-Estimated electric power required by each vehicle category to be recharged [1]

\begin{tabular}{|c|r|r|r}
\hline \multirow{2}{*}{} & \multicolumn{1}{|c|}{ Size } & \multicolumn{2}{c}{ Power required to the grid } \\
\cline { 2 - 5 } & & Standard $(\mathrm{kW})$ & $\begin{array}{r}\text { Industrial plug-in } \\
(\mathrm{kW})\end{array}$ \\
\hline \multirow{3}{*}{$\approx$} & Small & 2.2 & $6 \epsilon$ \\
\cline { 2 - 5 } & Mid-size & 4.4 & 133 \\
\cline { 2 - 5 } & Large & 7.8 & 233 \\
\hline \multicolumn{2}{|c|}{ Light Duty Vehicles } & 4.4 & 133 \\
\hline
\end{tabular}

The charging structure of existing automobiles depends on the country where cars are produced, but basically consists of a single phase or a three phase rectifier supplying a DC/DC converter which regulates the charge of car batteries[10-11]. Table 1 shows a summary of the main features of full electric vehicles that we may find plugged to our grids and table 2 offers an overview of the expected power to be delivered during the charging operation.

In this paper we shall analyze a supply installation to supply up to 70 vehicles. Most of them were Piaggio Porter, supplied through single phase chargers and there were only a few plugs for three phase vehicles (FIAT Ducato).

\section{Preliminary test of vehicle charging process}

The typical charging process of an EV follows a profile as given in fig. 1.

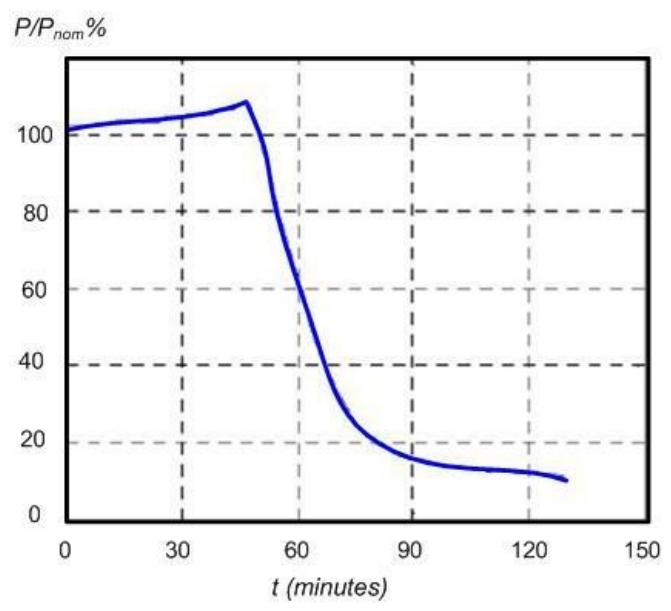

Fig. 1.- Load profile of an EV charger [9]

To determine the needs of the supply installation we first performed an individual test of the two types of vehicle chargers to be connected in the supply installation, namely a $2,2 \mathrm{~kW}$ single phase and a $6,6 \mathrm{~kW}$ three phase chargers. Foreseeing that the current would present a high level of harmonics and a high peak value, we tested the supply in two conditions: a) Direct connection to the charger and b) Inserting a reactor with a rated voltage drop of $4 \%$ at $50 \mathrm{~Hz}$. The results are presented in figs. 2 and 3 below. 


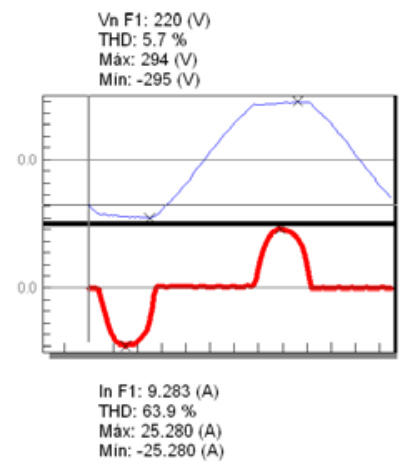

a) Direct supply

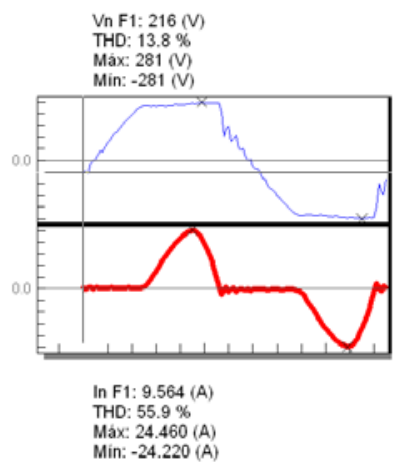

b) With a $4 \%$ reactor

Fig. 2.- Vehicle charger supplied by a single phase source

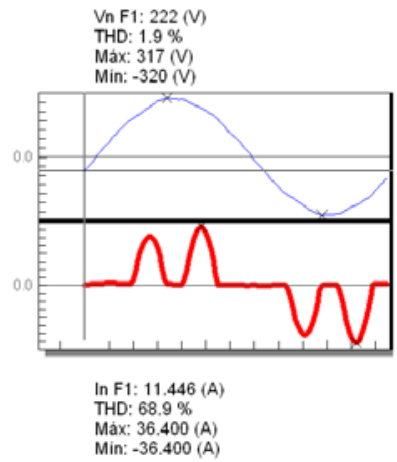

a) Direct supply

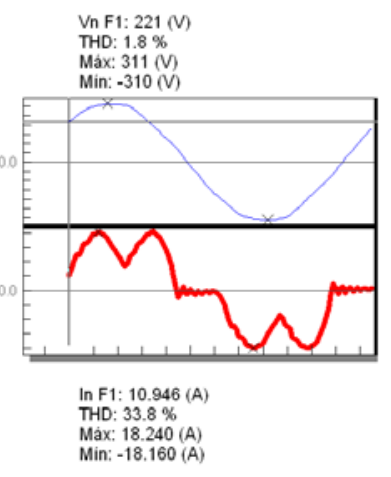

b) With a $4 \%$ reactor

Fig. 3.- Vehicle supplied by a three phase source

At the top we can see the voltage wave and the most relevant values and at the bottom the corresponding current wave and values. VnF1 and InF1 are RMS values of fundamental component of voltage and current respectively, and Max, Min are the peak values for each wave

From the recordings on a single vehicle we may deduce that in the supply of single phase charging systems, the addition of a series reactor rated $4 \%$ does not help very much improving the peak and the THD of the supply current, while in the three phase charger, the addition of a reactor with the same voltage drop significantly improves the situation (peak and THD decrease to $50 \%$ approximately).

\section{Supply design for a parking facility.}

As announced in the abstract, the goal of the investigation described in this paper was to elaborate a design guide for parking facilities, where a large number of EV and PHEV could be connected, without disturbing the supply system. The case study was a garage where several garbage trucks were parked during midday rest and during the whole night. Most of the vehicles were single phase and only a few were three phase. The total supply points were distributed on three lines having 20 points for single phase chargers and a total of 5 points for three phase chargers. The single wire diagram is represented in fig. 4 . The single phase chargers were designed to be connected directly to line-neutral supply lines and the three phase chargers were designed to be connected through a $4 \%$ reactor each. The analysis of individual vehicles and the high number of single phase supply points made foresee that there would be a high contents of third harmonic current, which 
would produce high current values in the neutral line (see harmonics contents for the individual vehicle in Table 3).

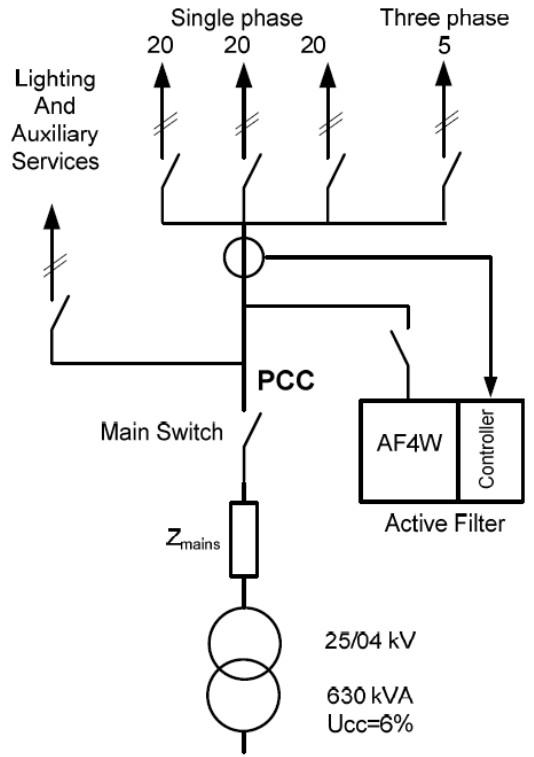

Fig. 4.- Single wire diagram of parking facility

Table 3.- Current harmonics contents of a single phase charger

\begin{tabular}{|c|c|c|}
\hline \multicolumn{3}{|c|}{ Corriente fase 1} \\
\hline \multicolumn{2}{|l|}{ Irms (A):12.335 } & THD (\%):64.3 \\
\hline \multicolumn{2}{|c|}{ Fundamental (A):9.442 } & Desfase $[9]: 0.8$ \\
\hline Armónico & Amplitud [\%] & Desfase ["] \\
\hline $2[+]$ & 0.214 & 157.3 \\
\hline $3[-]$ & 73.982 & 144.8 \\
\hline $4[-]$ & 0.151 & 314.4 \\
\hline $5[+]$ & 35.301 & 321.0 \\
\hline $6[+]$ & 0.204 & 89.3 \\
\hline $7[+]$ & 2.969 & 127.4 \\
\hline $8[+]$ & 0.253 & 187.0 \\
\hline $9[+]$ & 12.441 & 134.8 \\
\hline $10[+]$ & 0.199 & 354.3 \\
\hline $11[-]$ & 10.993 & 305.4 \\
\hline $12[+]$ & 0.010 & 54.3 \\
\hline $13(-)$ & 3.000 & 90.9 \\
\hline $14(-)$ & 0.137 & 158.0 \\
\hline $15[-]$ & 4.145 & 142.5 \\
\hline $16[-]$ & 0.069 & 359.3 \\
\hline
\end{tabular}

Because of the high contents of third harmonic, a shunt active filter was planned to be placed at the head of the supply system to avoid over-current in the neutral and to avoid the transformer declassing. The prediction of currents to be cancelled by the filter can be done by using the data of table 3 . The individual contents of harmonics in amperes can be calculated by (1), where, $I_{h}$ is the total RMS current of harmonic $h$ expected at the point of common 
coupling of supply to public grid (PCC) and $N v$ is the number of vehicles to be charged simultaneously.

The total RMS current needed in the active filter can be calculated by (2), where $I_{Q}$ is the reactive component of fundamental current

$$
\begin{aligned}
& I_{h}=I_{1} \cdot \frac{\text { Amplitud } \%}{100} \cdot N v \\
& I_{R M S_{-} \text {filt }}=\sqrt{I_{Q}^{2}+\sum I_{h}^{2}}
\end{aligned}
$$

Notice, that the reactive current in charging installations may be leading current and therefore, in some cases the filter is asked to supply lagging current to obtain the proper $\cos \varphi$.

\section{Supply facility simulation and test}

Although the design values could easily be predicted by the previous analysis, the supply facility supply system was simulated by using MATLAB - Simulink and the toolbox Sim Power Systems.

After the supply system installation and start up, several tests were performed confirming the simulation results. To allow the filter disconnection the load for testing was limited to about 100kW shared between the three phases.

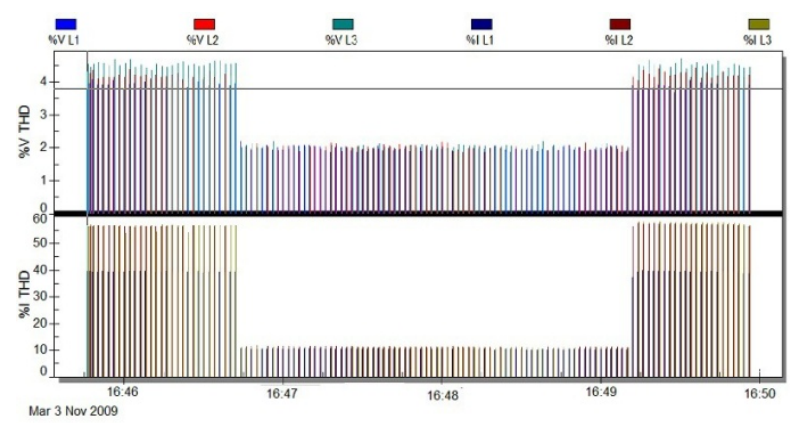

Fig. 5.- $T H D(V) \%$ and $T H D(I) \%$ without and with the active filter

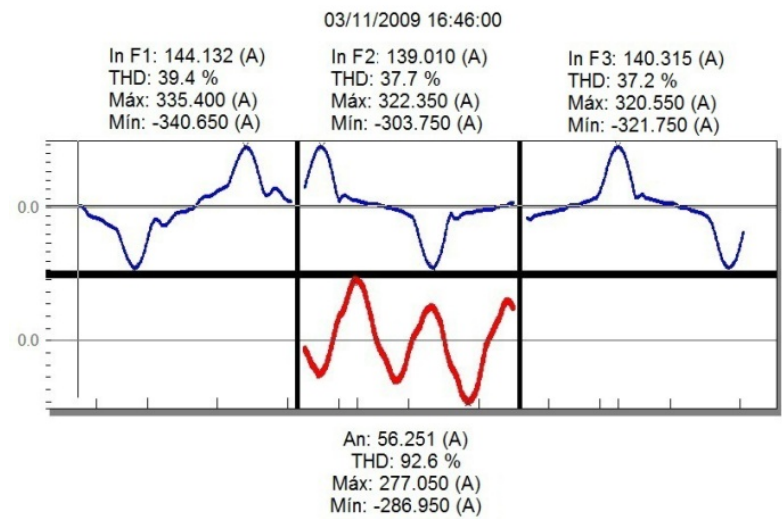

Fig. 6.- Currents in the three phases and neutral without the active filter 


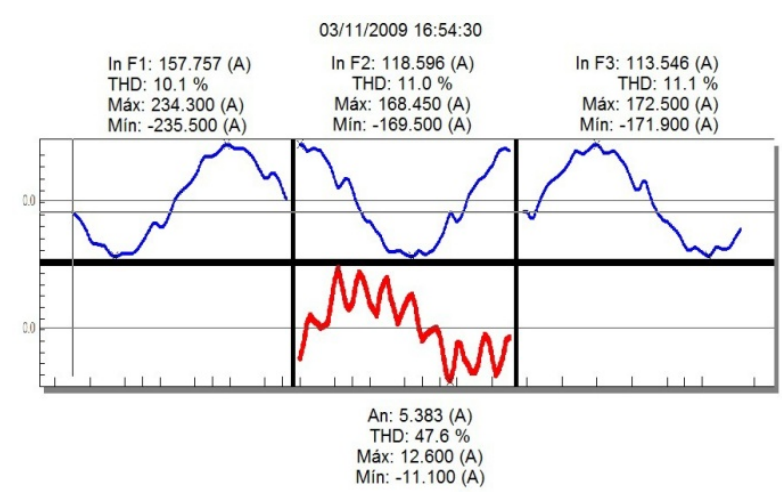

Fig. 7.- Currents in the three phases and neutral with

The most relevant test results are presented in figs. 5 to 7 , which correspond to data taken at the PCC with and without the active filtering. Such tests show the following important features of the proposed supply system design:

a) According to fig. 5 the $\mathrm{THD}(\mathrm{V})$ decreases from $4,5 \%$ to something below $2 \%$ and the $\mathrm{THD}(\mathrm{I})$ in the phase currents decreases from $60 \%$ to something below $10 \%$.

b) The comparison of figs. 6 and 7 show that the peak current in phase 1 for example decreases from $340 \mathrm{~A}$ to $235 \mathrm{~A}$. In this point we must remark that the filter is programmed to give about $35 \mathrm{kvar}$ of leading current to compensate the lighting and other parallel loads.

c) The RMS current in the neutral line decreases from 56A, with a total distortion close to $93 \%$ to approximately $5 \mathrm{~A}$ with a distortion close to $47 \%$.

\section{Conclusions}

The supply of a huge amount of Evs or PHEVs in parking and recharge facilities generates a serious problem for the supply system of such facilities. The main problems are generated in facilities to supply single phase vehicles, which consumption involves a big amount of third harmonic, thus forcing to oversize the neutral conductors and the supply transformers to avoid very high peak currents and overheating of the supply system.

The use of three phase reactors for the vehicles charging through three phase rectifiers and the use of active filters at the PCC of such installations can avoid the above mentioned problems and improve the efficiency of the charging installations.

\section{Acknowledgement}

The authors would like to acknowledge the firm

CIRCUTOR for providing the instruments, the test devices and the analysis software for the case study

\section{References}

[1] Perujo. A and Ciuffo. B, "Potential Impact of Electric Vehicles on the Electric Supply System: A case study for the Province of Milan, Italy, ISBN 978-92-79-13179-0, ISSN 1018-5593, DOI 10.2788/31623,", Joint Research Centre, Institute for Environment and Sustainability, European Commission,, Italy2009. 
[2] S. De Breucker, et al., "Grid Power Quality Improvements Using Grid-Coupled Hybrid Electric Vehicles PEMD 2006," in Power Electronics, Machines and Drives, 2006. The 3rd IET International Conference on, 2006, pp. 505-509.

[3] K. Clement-Nyns, et al., "The Impact of Charging Plug-In Hybrid Electric Vehicles on a Residential Distribution Grid," Power Systems, IEEE Transactions on, vol. 25, pp. 371-380, 2010.

[4] T. Winkler, et al., "Electric vehicle charging stations in Magdeburg," in Vehicle Power and Propulsion Conference, 2009. VPPC '09. IEEE, 2009, pp. 60-65.

[5] E. Valsera-Naranjo, et al., "Electrical vehicles: State of art and issues for their connection to the network," in Electrical Power Quality and Utilisation 2009. EPQU 2009. 10th International Conference on, 2009, pp. 1-3.

[6] G. A. Putrus, et al., "Impact of electric vehicles on power distribution networks," in Vehicle Power and Propulsion Conference, 2009. VPPC'09. IEEE, 2009, pp. 827-831.

[7] K. Clement, et al., "Coordinated charging of multiple plug-in hybrid electric vehicles in residential distribution grids," in Power Systems Conference and Exposition, 2009. PSCE '09. IEEE/PES, 2009, pp. 1-7. [8] S. W. Hadley, "Evaluating the impact of Plug-in Hybrid Electric Vehicles on regional electricity supplies," in Bulk Power System Dynamics and Control - VII. Revitalizing Operational Reliability, 2007 iREP Symposium, 2007 pp. 1-12.

[9] Y. Lu and J Jiang, "Harmonic-study of electric vehicle chargers," in Electrical Machines and Systems, 2005. ICEMS 2005. Proceedings of the Eighth International Conference on, 2005, pp. 2404-2407 Vol. 3.

[10] X. Zhou, et al., "A comparison of converter topologies for vehicle-to-grid applications: Three-leg converter versus H-bridge converter," in Industrial Electronics, $2009 . \quad$ IECON '09 35th Annual Conference of IEEE, 2009, pp. 3711-3716.

[11] X. Zhou, et al., "Design and control of grid- connected converter in bi-directional battery charger for Plug-in hybrid electric vehicle application," in Vehicle Power and Propulsion Conference, 2009. VPPC '09. IEEE, 2009, pp. 1716-1721. 